\title{
Seroprevalencia de Toxocara canis en perros de las ciudades de Corrientes y Esperanza (Argentina)
}

\author{
García, L.D. ${ }^{1}$; López, M.A. ${ }^{2}$; Laffont, H.M. ${ }^{1}$; Bojanich, M.V. ${ }^{2}$; Martín, U. ${ }^{3}$
}

${ }^{1}$ Cátedra de Inmunología, Facultad de Ciencias Veterinarias, Universidad Nacional del Nordeste (UNNE), Cabral 2139, Corrientes (3400), Argentina. ${ }^{2}$ Área de Inmunología, Instituto de Medicina Regional, Resistencia,

Chaco, Argentina. ${ }^{3}$ Centro de Investigaciones sobre Endemias Nacionales, Facultad de Bioquímica, Universidad Nacional del Litoral, Santa Fe. E-mail: ecnomartin@hotmail.com

\begin{abstract}
Resumen
García, L.D.; López, M.A.; Laffont, H.M.; Bojanich, M.V.; Martín, U.: Seroprevalencia de Toxocara canis en perros de las ciudades de Corrientes y Santa Fe (Argentina). Rev. vet. 25: 2, 131-134, 2014. Toxocara canis es un nematode de los caninos, que accidentalmente afecta al hombre provocando una enfermedad parasitaria zoonótica denominada toxocariasis. Los cachorros son responsables de la contaminación del ambiente a través de la eliminación de huevos infectantes al medio, mientras que las perras adultas representan un potencial reservorio, por ser capaces de transmitir verticalmente el parásito a sus crías. La infección en seres humanos constituye un problema sanitario de gran interés, principalmente por su impacto en niños. Los estudios coproparasitológicos en perros adultos han demostrado ser poco eficientes para detectar la infección. El objetivo de este estudio fue determinar valores de seroprevalencia de anticuerpos anti-T. canis en caninos de dos ciudades de Argentina. Se estudiaron perros de diferentes barrios de las ciudades de Corrientes y Esperanza. Se realizó el test de ELISA indirecto para detección de anticuerpos de tipo IgG específicos para T. canis. En Corrientes se estudiaron 119 perros. El análisis reveló que el 84,9\% (n=101) de los canes presentaba serología positiva. En Esperanza se estudiaron 82 perros; el ELISA indirecto reveló que el $51,2 \%(\mathrm{n}=42)$ del total de los canes presentaban serología positiva para este parásito. Los valores hallados son consistentes con los encontrados por otros autores en estudios similares, y no así con aquellos en los que se emplearon métodos directos para detección de huevos en heces, los cuales en general informan valores menores de prevalencia. La alta seroprevalencia hallada sugiere la necesidad de implementar medidas de control de la infestación en perros y de esa manera reducir el riesgo de transmisión al hombre.
\end{abstract}

Palabras clave: canino, Toxocara canis, seroprevalencia, zoonosis, Argentina.

\begin{abstract}
García, L.D.; López, M.A.; Laffont, H.M.; Bojanich, M.V.; Martín, U.: Seroprevalence of Toxocara canis in dogs from Corrientes and Santa Fe (Argentina). Rev. vet. 25: 2, 131 134, 2014. Toxocara canis is a nematode of canines, which accidentally affects man causing a zoonotic parasitic disease called toxocariasis. Puppies are responsible for pollution of the environment through the elimination of infective eggs in the soil, while adult dogs are a potential reservoir. The latter are able to vertically transmit the parasite to their offspring. Human infection is a health problem of great interest due to its impact on children. The parasitological studies in adult dogs have proven to be not effective to detect infection. The aim of this study was to determine values of seroprevalence of anti-T. canis antibodies in dogs from two cities of Argentina. Dogs of different neighborhoods of Corrientes and Santa Fe cities were studied. Indirect ELISA test for detection of specific IgG antibodies to T. canis was performed. In Corrientes 119 dogs were studied; the analysis revealed that $84.9 \%(n=101)$ had positive serology. In Santa Fe 82 dogs were studied; the indirect ELISA revealed that $51.2 \%(n=42)$ had positive serology for this parasite. These results are consistent with those found by other authors in similar studies, and different to those in which direct methods for detection of eggs in feces were used, which generally report lower prevalence rates. The high seroprevalence found suggests the need to implement measures to control the infestation in dogs and to reduce the risk of transmission to humans.
\end{abstract}

Key words: dog, Toxocara canis, seroprevalence, zoonoses, Argentina. 


\section{INTRODUCCIÓN}

Toxocara canis es un nematode de los caninos, que accidentalmente afecta al hombre provocando una enfermedad parasitaria zoonótica denominada toxocariasis. Existen tres especies de Toxocara que infectan a perros y gatos: T. canis, frecuente en perros y otros cánidos, Toxocara cati, propia de gatos y otros felinos y Toxascaris leonina presente en perros, gatos y otras especies $^{10}$.

Los caninos se infectan con T. canis por ingestión de huevos del parásito dispersos en el suelo, por ingestión de tejidos de huéspedes paraténicos infectados con larvas, por migración transplacentaria de larvas de la hembra preñada a sus fetos o por ingestión de larvas con la leche por pasaje transmamario ${ }^{5,10}$.

Cuando los cachorros ingieren huevos infectantes, las larvas atraviesan la mucosa intestinal, penetran en los vasos linfáticos y sanguíneos y alcanzan el hígado. Por vía sanguínea llegan a corazón y pulmones, ascendiendo por el árbol bronquial hasta la faringe, donde son deglutidas. Luego de dos mudas adicionales, completan su desarrollo a vermes adultos en el intestino delgado y los huevos aparecen en las heces 4-5 semanas después de contraída la infección. Este circuito se denomina migración traqueal ${ }^{7,10,12}$.

Las perras adultas representan un potencial reservorio, al ser capaces de transmitir verticalmente el parásito a sus crías. En ellas ocurre una migración somática, pudiendo las larvas permanecer en los tejidos -en estado de latencia- durante varios años ${ }^{10,12}$. En la perra gestante la larva se reactiva por estimulación hormonal y migra a la placenta y glándulas mamarias. La infección prenatal de cachorros ocurre cuando las larvas de la madre migran hacia ellos a través de la placenta. Las larvas permanecen en el hígado de los cachorros hasta el nacimiento, momento en que pasan a los pulmones, alcanzan la tráquea y maduran en intestino. Los huevos se expulsan con las heces a partir de la cuarta semana de vida del cachorro, que se convierte en responsable de la contaminación del ambiente a través de la eliminación de huevos infectantes al medio ${ }^{8}$.

El hombre adquiere la infección de manera accidental al tomar contacto con los huevos embrionados presentes en el suelo. Una vez dentro del organismo, la larva liberada del huevo inicia su migración somática acantonándose en diferentes órganos como hígado, pulmones, corazón, ojo y cerebro. La larva va dejando a su paso huellas de hemorragia, necrosis e inflamación con predominio de eosinófilos. En el ojo la respuesta inflamatoria puede conducir al desprendimiento total o parcial de la retina con pérdida de la visión ${ }^{5}$. Actualmente la afección en seres humanos constituye un problema sanitario de gran interés, principalmente por su impacto en niños.

El enzimoimnunoensayo (ELISA) representa hoy la principal herramienta inmunológica utilizada para el diagnóstico de toxocariasis humana. Ampliamente difundida, esta técnica basada en la detección de anti- cuerpos específicos de tipo inmunoglobulina $\mathrm{G}$ (IgG) anti $T$. canis, ha demostrado tener una alta sensibilidad y especificidad ${ }^{2}$. Los estudios coproparasitológicos en perros adultos podrían resultar poco eficientes para detectar la infección ya que los parásitos realizan una migración somática permaneciendo en latencia ${ }^{6}$.

El objetivo de este estudio fue determinar, mediante sero-inmuno-diagnóstico, valores de prevalencia de anticuerpos anti-T. canis, en perros de dos ciudades de la República Argentina.

\section{MATERIAL Y MÉTODOS}

Se estudiaron caninos de diferentes barrios de las ciudades argentinas de Corrientes (Provincia de Corrientes) y Esperanza (Provincia de Santa Fe) durante el periodo comprendido entre los meses de marzo y diciembre del año 2012. Los animales fueron trasladados por sus dueños a jornadas de castración en Corrientes y al hospital de la Facultad de Veterinaria de Esperanza. Se obtuvieron 3 mililitros de sangre por punción de la vena cefálica antebraquial, obteniéndose suero mediante centrifugación, el cual fue conservado a $-20^{\circ} \mathrm{C}$ hasta su utilización. Se consignaron datos de edad, sexo, raza y barrio de procedencia de los animales. Las muestras fueron analizadas en el área de Inmunología del Instituto de Medicina Regional (Resistencia, Argentina).

Se realizó el test de ELISA indirecto para detección de anticuerpos de tipo IgG específicos para T. canis, empleando antígeno de excreción/secreción (Ag TES) preparado a partir de cultivo de larvas del segundo estadio de Toxocara canis desarrolladas a partir de huevos embrionados, según técnica convencional ${ }^{4,11}$.

Se utilizaron anticuerpos anti IgG canina marcados con peroxidasa. Para ello se sensibilizaron placas de poliestireno de fondo plano (NUNC-MaxiSorp) con 100 ul de una solución de Ag TES en buffer de acoplamiento $\left(\mathrm{NaCO}_{3} \mathrm{pH} 9,6\right)$ y se incubaron a $4^{\circ} \mathrm{C}$ toda la noche. Luego se lavaron 10 veces con buffer PBS y se procedió al bloqueo de los sitios activos con $100 \mathrm{ul} \mathrm{de}$ una solución de leche descremada al 5\% en buffer TBSTween 20, pH 7,3. Se incubaron 2 horas a $37^{\circ} \mathrm{C}$ y luego se lavaron con buffer PBS. Las placas sensibilizadas se conservaron varios días a $4^{\circ} \mathrm{C}$, hasta su uso.

Los sueros caninos a estudiar y los sueros controles positivo y negativo se diluyeron en buffer TBSTwen-20 al 0,2\%, pH 7,3 con 1\% de leche descremada. La placa se incubó $45 \min$ a $37^{\circ} \mathrm{C}$, se lavó 10 veces con PBS y se le agregaron 100 ul de una solución de suero anti IgG canina conjugada con peroxidasa (Santa Cruz Biotechnologies $\left(\right.$ ). Luego se incubó $45 \mathrm{~min}$ a $37^{\circ} \mathrm{C}$, se lavó 10 veces con PBS y se le agregaron 100 ul del reactivo cromógeno $\mathrm{H}_{2} \mathrm{O}_{2}$-orto-fenildiamina (Sigma Chemical Co, USA $\AA$ ) al $0,06 \%$, preparado en el momento de usar. El lapso de reacción se fijó en 30 minutos a temperatura ambiente y en la oscuridad, y se detuvo con 50 ul de $\mathrm{H}_{2} \mathrm{SO}_{4} 1 \mathrm{~N}$. La lectura espectrofotométrica se efectuó a $450 \mathrm{~nm}$. La concentración óptima de antígeno TES fue de $0,16 \mathrm{ug} / \mathrm{ml}$ en buffer de acoplamiento, 
la dilución óptima del suero fue 1/100 y la dilución del conjugado $1 / 5000$.

Para los cálculos estadísticos se empleó el software EpiInfo versión 6.0. Se efectuaron estadísticas descriptivas paramétricas de tendencia central (media aritmética) y dispersión (desvío estándar). Para comparación de proporciones se aplicó el test de chi cuadrado. El valor de corte se calculó como la media aritmética de las densidades ópticas de un lote de sueros control negativos, mas dos desviaciones estándares. Para todas las inferencias se fijó un nivel de riesgo alfa $=5 \%$, por debajo del cual se rechazó la hipótesis nula de igualdad.

\section{RESULTADOS Y DISCUSIÓN}

En Corrientes se estudiaron 119 perros (11 machos y 108 hembras) de edades comprendidas entre 5 meses y 7 años $(\bar{x}=2,5$ años). El análisis reveló que el $84,9 \%$ de los canes (101) presentó serología positiva para $T$. canis. No hubo diferencias significativas entre sexos $(\mathrm{p}=0,88)$. Al agruparlos por edad se constató que en la franja etaria de 0 a 6 meses $(\mathrm{n}=8)$ la seroprevalencia fue del $62,5 \%$, de 7 a 12 meses ( $n=38): 84,2 \%$, de 13 a 36 meses $(\mathrm{n}=42): 88 \%$ y 37 meses en adelante $(\mathrm{n}=31)$ : $87 \%$. No hubo diferencias significativas entre dichas seroprevalencias $(p=0,30)$.

En Santa Fe se estudiaron 82 perros (4 machos y 78 hembras) de edades comprendidas entre 3 meses y 10 años $(\bar{x}=2$ años). No hubo diferencias significativas entre sexos $(p=0,64)$. El ELISA indirecto reveló que el $51,2 \%(\mathrm{n}=42)$ del total de los canes presentaron serología positiva para este parásito. Al estratificar por edad se verificó que en la franja etaria de 0 a 6 meses $(n=20)$ la seroprevalencia fue del $40 \%$, de 7 a 12 meses $(n=31)$ : $45,2 \%$, de 13 a 36 meses $(n=16): 56,3 \%$ y de 37 a 120 meses $(n=15): 73,3 \%$. En este caso se registraron diferencias significativas entre las franjas etarias $(p=0,03)$.

Los resultados obtenidos demuestran que existe una elevada seroprevalencia a $T$. canis entre los caninos estudiados, principalmente en la ciudad de Corrientes. Los valores concuerdan con los reportados en la ciu-

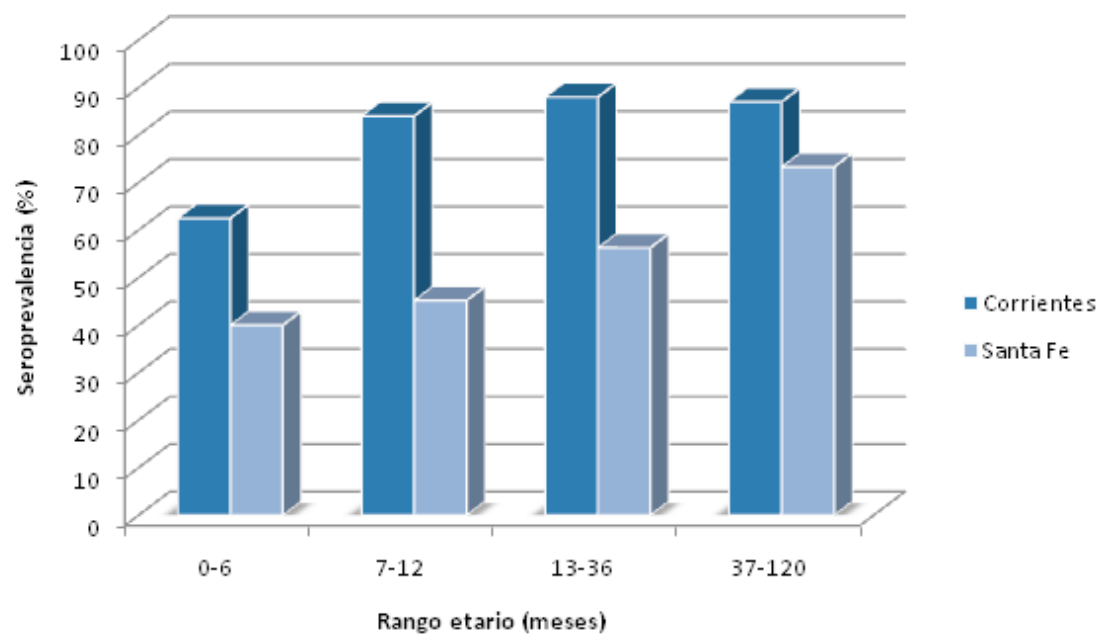

Figura 1. Seroprevalencia de anticuerpos anti T. canis según rango etario. dad de Salvador, Brasil, donde se obtuvo un $82 \%$ de positividad en sueros de caninos mediante enzimoinmunoanálisis ${ }^{13}$. Dicho valor se aproxima al obtenido anteriormente por nuestro grupo de trabajo en caninos de áreas rurales, donde la seroprevalencia fue de $87 \%$.

Las importantes diferencias $(p<0,0001)$ halladas con respecto a la seroprevalencia entre las ciudades estudiadas (Figura 1), pueden atribuirse al mayor control sanitario de los canes oriundos de Esperanza. Con respecto al sexo, los resultados podrían estar influenciados por la gran predominancia de hembras en la muestra. En cuanto a la estratificación etaria se observó un incremento de la seroprevalencia con la edad de los animales de ambas ciudades.

Hasta el momento no se encontraron en Argentina datos de estudios serológicos realizados en caninos con los cuales comparar los resultados obtenidos. Estudios de heces caninas presentes en las aceras de la ciudad de Corrientes en el año 2005, arrojaron prevalencias de hasta un $16 \%{ }^{9}$. A partir de estudios similares realizados en las ciudades de Mar del Plata ${ }^{1}$ y La Plata ${ }^{3}$, se informaron valores de 22,2 y $13,3 \%$, correspondientes a presencia de parásitos en materia fecal de plazas públicas y de contaminación con huevos de $T$. canis respectivamente.

La técnica ELISA arrojó valores que se relacionan en mayor medida con las características de patogenia que presenta la toxocariasis en los canes. Este enzimoinmunoensayo podría ser utilizado en estudios epidemiológicos de seroprevalencia, pudiendo también ser una importante herramienta en la búsqueda de antígenos candidatos para la preparación de futuras vacunas.

Cabe destacar que los valores obtenidos a partir de este estudio difieren notablemente de aquéllos en los que se emplearon métodos directos para detección de huevos en heces, los cuales en general informan menor prevalencia. En este sentido concordamos con el concepto de que estos últimos estudios estarían subestimando la prevalencia de la infección por T. canis, ya que el examen fecal no detecta la mayoría de los caninos adultos infectados que en general no elimina los huevos del parásito ${ }^{6}$.

La alta seroprevalencia hallada sugiere la necesidad de implementar medidas de control de la infestación en perros y de esa manera reducir el riesgo de transmisión al hombre.

Agradecimientos. Por su valioso aporte en la obtención y envío de muestras, a N. Widerhorn y S. Pepino, directoras del Hospital de Pequeños Animales de la Facultad de Ciencias Veterinarias de la Universidad Nacional del Litoral (Esperanza, Argentina). 


\section{REFERENCIAS}

1. Andresiuk MV, Denegri GM, Esardellla NH, Hollmann P. 2003. Encuesta coproparasitológica canina realizada en plazas públicas de la ciudad de Mar del Plata, Buenos Aires, Argentina. Parasitol Latinoam 58: 17-22.

2. De Savigny D, Voller A, Woodruff W. 1979. Toxocariasis: serological diagnosis by enzyme immunoassay. J Clin Pathol 32: 284-288.

3. Fonrouge R, Guardis MV, Radman NE, Archelli SM. 2000. Contaminación de suelos con huevos de Toxocara $s p$ en plazas y parques públicos de la ciudad de La Plata, Buenos Aires, Argentina. Bol Chil Parasitol 55: 3-4.

4. Gillespie SH, Bidwell D, Voller A, Robertson BD, Maizels RM. 1993. Diagnosis of human toxocariasis by antigen capture enzyme linked immunosorbent assay. J Clin Pathol 46: 551-554.

5. Glickman L, Schantz P. 1981. Epidemiology and pathogenesis of zoonotic toxocariasis. Epidem Rev 3: 230-250.

6. Glickman LT, Magnaval JF. 1993. Zoonotic roundworm infections. Infect Dis Clin North Am 7: 717-732.

7. Magnaval JF, Glickman LT, Dorchies P, Morassin B. 2001. Highlights of human toxocariasis. Korean J Parasitol 39: 1-11.
8. Meléndez E, Sánchez J. 2004. Parasitología Médica Básica, 2da ed., Editorial Fundaeduco, Barquisemeto (Venezuela), p. 45-49.

9. Milano AM, Oscherov EB. 2005 Contaminación de aceras con enteroparásitos caninos en Corrientes, Argentina. Parasitol Latinoam 60: 82-85.

10. Minvielle MC, Niedfeld G, Ciarmela ML, Basualdo JA. 1999. Toxocariasis causada por Toxocara canis: aspectos clinicoepidemiológicos. Enferm Infecc Microbiol Clin 17: 300-306.

11. Oaks JK, Kayes SG. 1979. Artificial hatching and culture of Toxocara canis second stage larvae. J Parasitol 65: 969970.

12. Overgaauw P. 1997. Aspects of Toxocara epidemiology: human toxocariosis. Crit Rev Microbiol 23: 215-231.

13. Regis SC, Mendonça LR, Silva S, Dattoli VC, Alcântara NM, Barrouin SM. 2011. Seroprevalence and risk factors for canine toxocariasis by detection of specific IgG as a marker of infection in dogs from Salvador, Brazil. Acta Trop 120: 46-51. 